Check for updates

Cite this: J. Mater. Chem. B, 2019, 7, 305

Received 22nd September 2018, Accepted 27th November 2018

DOI: $10.1039 / c 8 t b 02494 d$

rsc.li/materials-b

\title{
Imaging of anti-inflammatory effects of HNO via a near-infrared fluorescent probe in cells and in rat gouty arthritis model $\dagger$
}

\author{
Yan Huang, ${ }^{\mathrm{ab}}$ Xia Zhang, ${ }^{\mathrm{bc}} \mathrm{Na} H \mathrm{He},{ }^{\mathrm{b}}$ Yue Wang, ${ }^{\mathrm{bc}}$ Qi Kang, ${ }^{* a}$ Dazhong Shen, (D) ${ }^{\mathrm{a}}$ \\ Fabiao Yu (D)*bd and Lingxin Chen (D) *be
}

\begin{abstract}
Nitroxyl (HNO) plays a crucial role in anti-inflammatory effects via the inhibition of inflammatory pathways, but the details of the endogenous generation of HNO still remain challenging owing to the complex biosynthetic pathways, in which the interaction between $\mathrm{H}_{2} \mathrm{~S}$ and $\mathrm{NO}$ simultaneously generates $\mathrm{HNO}$ and polysulfides $\left(\mathrm{H}_{2} \mathrm{~S}_{n}\right)$ in mitochondria. Moreover, nearly all the available fluorescent probes for $\mathrm{HNO}$ are utilized for imaging $\mathrm{HNO}$ in cells and tissues, instead of the in situ real-time detection of the simultaneous formation of $\mathrm{HNO}$ and $\mathrm{H}_{2} \mathrm{~S}_{n}$ in mitochondria and animals. Here, we have developed a mitochondria-targeting near-infrared fluorescent probe, namely, Mito-JN, to detect the generation of HNO in cells and a rat model. The probe consists of three moieties: Aza-BODIPY as a fluorescent signal transducer, a triphenylphosphonium cation as a mitochondria-targeting agent, and a diphenylphosphinobenzoyl group as an HNO-responsive unit. The response mechanism is based on an aza-ylide intramolecular ester aminolysis reaction with fluorescence emissions on. Mito-JN displays high selectivity and sensitivity for HNO over various other biologically relevant species. Mito-JN was successfully used for the detection of the endogenous generation of $\mathrm{HNO}$, which is derived from the crosstalk between $\mathrm{H}_{2} \mathrm{~S}$ and $\mathrm{NO}$ in living cells. The additional generation of $\mathrm{H}_{2} \mathrm{~S}_{n}$ was also confirmed using our previous probe $\mathrm{Cy}$-Mito. The antiinflammatory effect of HNO was examined in a cell model of LPS-induced inflammation and a rat model of gouty arthritis. The results imply that our probe is a good candidate for the assessment of the protective effects of $\mathrm{HNO}$ in inflammatory processes.
\end{abstract}

\section{Introduction}

As the one-electron-reduced and protonated congener of nitric oxide (NO), exogenous nitroxyl (HNO) has been confirmed to have the ability to exacerbate ischemia-related injury and induce neurotoxicity. ${ }^{1}$ However, endogenous HNO acts as a pharmacological agent that possesses distinct pharmacological properties from those of NO. ${ }^{2}$ Under biological conditions,

\footnotetext{
${ }^{a}$ College of Chemistry, Chemical Engineering and Materials Science, Key Laboratory of Molecular and Nano Probes, Ministry of Education, Shandong Normal University, Jinan 250014, China. E-mail: kangqi@sdnu.edu.cn ${ }^{b}$ Key Laboratory of Coastal Environmental Processes and Ecological Remediation, The Research Center for Coastal Environmental Engineering and Technology, Yantai Institute of Coastal Zone Research, Chinese Academy of Sciences, Yantai 264003, China. E-mail: fbyu@yic.ac.cn, lxchen@yic.ac.cn

${ }^{c}$ University of Chinese Academy of Sciences, Beijing 100049, China

${ }^{d}$ Institute of Functional Materials and Molecular Imaging, College of Emergency and Trauma, Hainan Medical University, Haikou 571199, China

${ }^{e}$ College of Chemistry and Chemical Engineering, Qufu Normal University, Qufu 273165, China

$\dagger$ Electronic supplementary information (ESI) available. See DOI: 10.1039/ c8tb02494d
}

HNO directly interacts with biothiols ${ }^{3}$ and then activates vascular voltage-dependent $\mathrm{K}^{+}$channels $\left(\mathrm{K}_{\mathrm{v}}\right)^{4}$ to increase the level of plasma calcitonin gene-related peptide (CGRP), which makes HNO an important potential therapeutic candidate for the treatment of heart failure. ${ }^{5} \mathrm{HNO}$ also induces the nitrosation of thiolates and releases zinc ions to trigger a series of zinc-related signalling pathways. $^{6,7}$ In addition to cardiovascular effects, HNO has recently been reported to possess anti-inflammatory effects. HNO inhibits inflammation-induced hyperalgesia in subcutaneous plantar tissue in rats and suppresses the carrageenan-induced production of cytokines. ${ }^{8}$ The anti-inflammatory effects of HNO in living cells are dependent on the inhibition of the NF- $\kappa \mathrm{B}$ and p38 MAPK pathways. ${ }^{9}$ In view of the critical physiological roles of HNO in cells and in vivo, it is necessary to clearly detect the endogenous generation of HNO in biological systems. Endogenous HNO can be produced via a heme iron-catalyzed reaction between $\mathrm{NO}$ and hydrogen sulfide $\left(\mathrm{H}_{2} \mathrm{~S}\right){ }^{10-12}$ However, the adjunctive use of HNO as a therapeutic agent for anti-inflammatory treatment needs further clarification.

Both hydrogen sulfide $\left(\mathrm{H}_{2} \mathrm{~S}\right)$ and $\mathrm{NO}$ are gaseous signaling mediators for the regulation of various biological functions. NO 
is generated by three NO synthase (NOS) isozymes in mitochondria with L-arginine as a substrate. ${ }^{13}$ At the molecular level, inflammation will increase the concentration of NO, mainly via the catalysis of inducible NOS (iNOS). ${ }^{14} \mathrm{H}_{2} \mathrm{~S}$ can be synthesized via enzymatic reactions that are catalyzed by cystathionine $\beta$-synthase (CBS), cystathionine $\gamma$-lyase (CSE) and 3-mercaptopyruvate sulfurtransferase (3-MST). ${ }^{15}$ 3-MST is constitutively expressed in mitochondria. ${ }^{16}$ Under stimulation by specific stresses (such as inflammation), CSE and CBS can be translocated into mitochondria to promote the production of $\mathrm{H}_{2} \mathrm{~S} .{ }^{17,18}$ Furthermore, the abundant heme iron centers in mitochondria are available for the formation of HNO via the reaction between $\mathrm{NO}$ and $\mathrm{H}_{2} \mathrm{~S}$. Therefore, mitochondria are considered to be the organelles where HNO is generated. Therefore, it is essential to develop efficient biochemical tools for the detection of the formation and metabolism of HNO in mitochondria. It is worth noting that the interaction of $\mathrm{H}_{2} \mathrm{~S}$ and NO can also produce polysulfides $\left(\mathrm{H}_{2} \mathrm{~S}_{n}\right) \cdot{ }^{19}$ The physiological functions of $\mathrm{H}_{2} \mathrm{~S}_{n}$ may facilitate anti-inflammatory effects. However, the simultaneous formation of $\mathrm{HNO}$ and $\mathrm{H}_{2} \mathrm{~S}_{n}$ remains to be confirmed.

The rapid dimerization and dehydration of HNO to nitrous oxide $\left(\mathrm{N}_{2} \mathrm{O}\right)$ always prevents the accurate detection of $\mathrm{HNO}$ in cells and in vivo. ${ }^{2}$ Therefore, reliable methods for the detection of the intracellular generation of HNO with excellent selectivity and high spatiotemporal resolution are greatly desired. Moreover, these methods must be suitable for the rapid in situ detection of HNO in living systems. Fluorescence bioimaging technology based on fluorescent probes has been recognized to be an effective tool for the in situ detection of bioreactive species in biological systems. ${ }^{20}$ Hitherto, two main types of fluorescent probe have been designed for the intracellular detection of HNO, which are based on: (i) the reduction of $\mathrm{Cu}$ (II) to $\mathrm{Cu}(\mathrm{I})^{21-30}$ and (ii) the bioorthogonal reaction of Staudinger ligation to form an aza-ylide. ${ }^{31-53}$ Although these HNO probes have enabled great achievements, new HNO probes are still needed to meet different new requirements in practical applications. As far as we know, there is a lack of fluorescent probes for the mitochondrial localization of HNO, because HNO is mainly produced in mitochondria. ${ }^{54}$ It is unfortunate that only one probe has been reported for imaging HNO that is derived from the reaction between $\mathrm{NO}$ and $\mathrm{H}_{2} \mathrm{~S} .{ }^{55}$ However, nearly all the probes that have been developed focus on the visual inspection of HNO in cells and tissues, instead of the in situ real-time detection of HNO in mitochondria and animals. ${ }^{54}$ Nearinfrared (NIR) fluorescence can deeply penetrate tissue and effectively avoid background noise. ${ }^{51}$ Therefore, the imaging of HNO in mitochondria and animals using a desirable mitochondriatargeting NIR probe is another considerable issue that must be addressed.

To meet the above challenges and further our previous research, ${ }^{35-37}$ we designed and synthesized a mitochondriatargeting NIR fluorescent probe, namely, Mito-JN, for the visualization of HNO in cells and in vivo. Mito-JN displayed high selectivity and sensitivity with a turn-on fluorescence response to HNO. The probe could exclusively accumulate in mitochondria and be used for monitoring the generation of endogenous HNO. We evaluated the proposed biosynthetic pathways by which HNO could be formed via the reaction between $\mathrm{NO}$ and $\mathrm{H}_{2} \mathrm{~S}$ in mitochondria. Moreover, the simultaneous formation of $\mathrm{H}_{2} \mathrm{~S}_{n}$ during the process of the production of HNO was also identified by our reported $\mathrm{H}_{2} \mathrm{~S}_{n}$ probe Cy-Mito. ${ }^{56}$ The results of flow cytometry confirmed that our probe could qualitatively and quantitatively detect intracellular HNO. Our results demonstrated that HNO possessed anti-inflammatory effects in a cell model of lipopolysaccharide (LPS)-induced inflammation and a rat model of gouty arthritis (GA). A western blotting assay and pathological sectioning were also performed to demonstrate the anti-inflammatory function of HNO.

\section{Results and discussion}

\section{Synthesis and design of the probe Mito-JN}

To design a desirable fluorescent probe for HNO, one must first take its selectivity and biocompatibility into account. Because derivatives of phosphine are abiotic and inert toward biomolecules, the reaction of phosphine with HNO based on Staudinger ligation has been extensively employed for the development of HNO probes. ${ }^{54}$ The reaction between HNO and triarylphosphine results in the corresponding phosphine oxide and aza-ylide. The aza-ylide will undergo an immediate intramolecular ester aminolysis reaction to release an alcohol/ amide. The proposed detection mechanism is outlined in Scheme 1. Using this reaction, we have successfully performed the imaging analysis of HNO in lysosomes, the endoplasmic reticulum and cytoplasm. ${ }^{35-37}$ In this study, we aimed to achieve the detection of the endogenous generation of $\mathrm{HNO}$ during $\mathrm{NO} / \mathrm{H}_{2} \mathrm{~S}$ crosstalk in mitochondria. Aza-BODIPY was employed as the fluorophore owing to its NIR absorption/emission. Aza-BODIPY also features high resistance to photobleaching, high membrane permeability, and a high fluorescence quantum yield. The HNO recognition unit was a diphenylphosphinobenzoyl group, and the integration of a lipophilic triphenylphosphonium cation enabled the probe to preferentially accumulate in mitochondria. ${ }^{57}$ HNO initially reacted with triarylphosphine to yield an aza-ylide intermediate, which then underwent an immediate intramolecular nucleophilic reaction on the carbonyl carbon to release the fluorophore (Scheme 1). The synthetic routes of the probe Mito$\mathrm{JN}$ are shown in the ESI $\dagger$ (Scheme S1). In brief, the fluorophore aza-BODIPY was synthesized according to our previous method. ${ }^{35}$ $\mathrm{An}_{\mathrm{N}} 2$ reaction with (4-bromobutyl)triphenylphosphonium bromide afforded the compound Mito-1, which was then subjected to esterification with 2-(diphenylphosphino)benzoic acid to yield

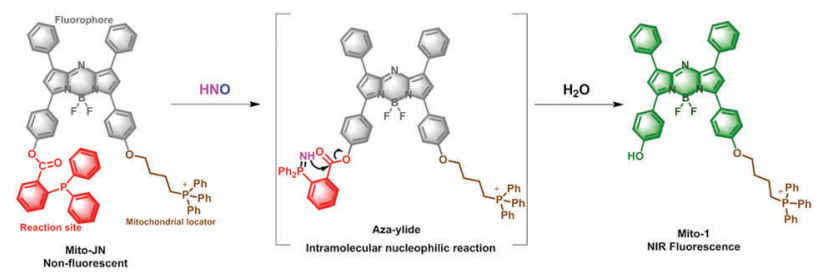

Scheme 1 Proposed mechanism of the reaction of Mito-JN with HNO. 
the final product, namely, Mito-JN. All the compounds were characterized by ${ }^{1} \mathrm{H}$ NMR, ${ }^{13} \mathrm{C}$ NMR, ${ }^{31} \mathrm{P}$ NMR and HRMS.

\section{Spectroscopic properties and selectivity}

We investigated the absorption spectra and the fluorescence spectral response of Mito-JN to HNO under simulated physiological conditions (10 mM HEPES buffer, $\mathrm{pH}=7.4$ ). Angeli's salt (AS) was employed as the source of HNO. The absorption of the probe Mito-JN was located in the NIR spectral region (Fig. S3, ESI $\dagger$ ). The maximum absorption wavelength was $680 \mathrm{~nm}$ with $\varepsilon=3.70 \times 10^{4} \mathrm{M}^{-1} \mathrm{~cm}^{-1}$. However, the addition of AS induced hardly any changes in absorption (Fig. S3, ESI $\dagger$ ). The fluorescence spectrum of Mito-JN in the presence of AS was next recorded to investigate the fluorescence response of the probe to HNO. As shown in Fig. 1a, the addition of AS (from 0 to $10 \mu \mathrm{M}$ ) triggered increases in the NIR fluorescence emission centered at $730 \mathrm{~nm}$. Therefore, the emission at $730 \mathrm{~nm}$ was selected as the optimal fluorescence intensity to quantify the fluorescence response of our probe to HNO. The calibration curve is shown in Fig. 1b. High linearity was observed for concentrations of AS in the range from 1 to $10 \mu \mathrm{M}$. The regression equation was $\Delta F_{730 \mathrm{~nm}}=$ 198262.1[AS] $(\mu \mathrm{M})+18297.5(r=0.9983)$. Under the given experimental conditions, the limit of detection ( $3 \sigma /$ slope) for HNO was determined to be $50 \mathrm{nM}$. The results suggested that Mito-JN had high sensitivity in the response to endogenous HNO. The probe Mito-JN had potential for applications in bioassays.

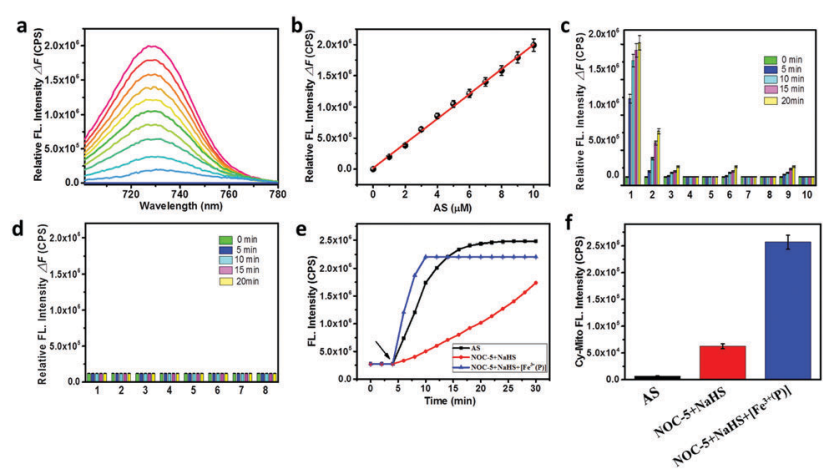

Fig. 1 (a) Fluorescence response of Mito-JN $(2 \mu \mathrm{M})$ to different concentrations of Angeli's salt (AS) with emissions in the range from 700 to $780 \mathrm{~nm}$. $\lambda_{\mathrm{ex}}=680 \mathrm{~nm}$. (b) Linear relationship between the relative fluorescence intensity at $730 \mathrm{~nm}$ and the concentration of AS $(0-10 \mu \mathrm{M})$. (c) Time-dependent fluorescence response of $2 \mu \mathrm{M}$ Mito-JN to the tested species in a HEPES buffer solution (10 mM, 0.5\% TW 80, pH 7.4): $1,10 \mu \mathrm{M} \mathrm{AS} ; 2$, $20 \mu \mathrm{M}$ GSNO; 3, $200 \mu \mathrm{M} \mathrm{ONOO}^{-} ; 4,50 \mu \mathrm{M} \mathrm{NOC}-5 ; 5,500 \mu \mathrm{M} \mathrm{NO}_{2}^{-} ; 6$, $200 \mu \mathrm{M} \mathrm{H}_{2} \mathrm{O}_{2} ; 7,100 \mu \mathrm{M} \mathrm{O}_{2}^{-} ; 8,20 \mu \mathrm{M} \mathrm{MeLOOH} ; 9,200 \mu \mathrm{M} \mathrm{ClO}^{-} ; 10$, $100 \mu \mathrm{M} \mathrm{Na}_{2} \mathrm{~S}_{4}$. (d) $1,50 \mu \mathrm{M}$ L-Cys; 2, $100 \mu \mathrm{M} \mathrm{GSH} ; 3,500 \mu \mathrm{M} \mathrm{NaHS} ; 4,200 \mu \mathrm{M}$ ascorbic acid; 5, $200 \mu \mathrm{M}$ tocopherols; 6, $50 \mu \mathrm{M} \mathrm{L-Arg;} \mathrm{7,} 200 \mu \mathrm{M}$ tyrosine (Tyr); $8,50 \mu \mathrm{M}$ hydroxylamine (HA). The bars represent the fluorescence intensity $0,5,10,15$, and $20 \mathrm{~min}$ after the addition of the respective compounds. (e) Time-dependent fluorescence response of the probe Mito-JN $(2 \mu \mathrm{M})$ to AS, $\mathrm{NOC}-5(1 \mathrm{mM})+\mathrm{NaHS}(100 \mu \mathrm{M})$ and NOC-5 + NaHS + $\left[\mathrm{Fe}^{3+}(\mathrm{P})\right](1 \mu \mathrm{M})$ over 30 min. (f) Detection of $\mathrm{H}_{2} \mathrm{~S}_{n}$ by fluorescence response of Cy-Mito $(2 \mu \mathrm{M})$ in AS, NOC-5 $(1 \mathrm{mM})+\mathrm{NaHS}(100 \mu \mathrm{M})$ and NOC-5 + NaHS + $\left[\mathrm{Fe}^{3+}(\mathrm{P})\right](1 \mu \mathrm{M})$ treated for $10 \mathrm{~min}$. Mito-JN: $\lambda_{\mathrm{ex}}=680 \mathrm{~nm}, \lambda_{\mathrm{em}}=730 \mathrm{~nm}$. Cy-Mito: $\lambda_{\mathrm{ex}}=$ $730 \mathrm{~nm}, \lambda_{\mathrm{em}}=780 \mathrm{~nm}$. The spectra were acquired in a HEPES buffer solution (10 mM, 0.5\% TW 80, pH 7.4).
We next tested the fluorescence response of Mito-JN to other physiologically related species in a HEPES buffer solution (10 mM, pH 7.4). As illustrated in Fig. 1c and d, the probe was incubated with various biospecies, including $S$-nitrosoglutathione (GSNO), $\mathrm{ONOO}^{-}$, NO (NOC-5), $\mathrm{NO}_{2}^{-}$, tocopherols, $\mathrm{H}_{2} \mathrm{O}_{2}, \mathrm{O}_{2}{ }^{-}$, methyl linoleate hydroperoxide, $\mathrm{ClO}^{-}, \mathrm{Na}_{2} \mathrm{~S}_{4}$ (a donor of $\mathrm{H}_{2} \mathrm{~S}_{n}$ ), L-cysteine (L-Cys), glutathione (GSH), NaHS, ascorbic acid, L-arginine (L-Arg), tyrosine, and hydroxylamine (HA). The fluorescence intensities were recorded at time points of $0,5,10,15$, and $20 \mathrm{~min}$. Only AS gave rise to a remarkable increase in the fluorescence emission at $730 \mathrm{~nm}$ within $10 \mathrm{~min}$, but GSNO, which was considered to react with phosphines and yield aza-ylides, exhibited rather slow reaction kinetics. In comparison with the fast response of HNO, GSNO would not strongly interfere with the detection of HNO. Biological reductants represented another major challenge for our examination, because they are usually present in high concentrations in cells. When biological reductants, such as GSH, ascorbic acid and NaHS, were added to the solution of Mito-JN in HEPES buffer, no obvious fluorescence signals were observed (Fig. 1d). The results confirmed that the fluorescence response induced by AS was due to the generation of HNO. Our results indicated that Mito-JN possessed excellent selectivity for HNO in the presence of various biologically relevant species under physiological conditions.

We next examined the ability of our probe to detect $\mathrm{HNO}$ derived from the interaction between $\mathrm{NO}$ and $\mathrm{H}_{2} \mathrm{~S}$. Assays were performed in HEPES buffer $(10 \mathrm{mM}, \mathrm{pH} 7.4)$ at $37{ }^{\circ} \mathrm{C}$ for $30 \mathrm{~min}$. NOC-5 was used as a donor of NO for the reaction with $\mathrm{H}_{2} \mathrm{~S}$ (NaHS) to generate $\mathrm{HNO}$ under the catalysis of a water-soluble porphyrin $\left[\mathrm{Fe}^{3+}(\mathrm{P})\right]$. As expected, the probe Mito-JN rapidly gave a fluorescence response to different sources of HNO (Fig. 1e). The result revealed that our probe could be utilized for the in situ detection of HNO that was generated from the crosstalk between $\mathrm{NO}$ and $\mathrm{H}_{2} \mathrm{~S}$, but the interaction involved a pathway catalyzed by heme iron. Although $\mathrm{H}_{2} \mathrm{~S}_{n}$ are additional common products of the $\mathrm{NO} / \mathrm{H}_{2} \mathrm{~S}$ crosstalk signaling pathway, until now they had not been directly detected using a fluorescent probe for $\mathrm{H}_{2} \mathrm{~S}_{n}$. We attempted to detect the generation of $\mathrm{H}_{2} \mathrm{~S}_{n}$. We used a recently developed fluorescent probe (Cy-Mito) ${ }^{56}$ for the in situ real-time detection of $\mathrm{H}_{2} \mathrm{~S}_{n}$. The results in Fig. 1f clearly demonstrate that the interaction between $\mathrm{H}_{2} \mathrm{~S}$ and NO generated $\mathrm{H}_{2} \mathrm{~S}_{n}$.

\section{Imaging of HNO and mitochondrial localization in cells}

We attempted to exploit the potential applicability of our probe for the detection of HNO in cells and in vivo. A standard MTT assay was performed to examine the cytotoxicity of Mito-JN. As shown in Fig. S5 (ESI $\dagger$ ), after they were incubated with $100 \mu \mathrm{M}$ Mito-JN for $24 \mathrm{~h}$ the cell viability of RAW264.7 cells was greater than $85 \%$ and the $50 \%$ cell survival concentration $\left(\mathrm{IC}_{50}\right)$ was predicted to be $320 \mu \mathrm{M}$, which indicated the low cytotoxicity of Mito-JN. We next investigated the ability of Mito-JN to detect HNO in living cells. Initially, RAW264.7 cells were incubated with $1 \mu \mathrm{M}$ Mito-JN for $20 \mathrm{~min}$ at $37{ }^{\circ} \mathrm{C}$. As controls, the cells exhibited no fluorescence, as shown in Fig. 2a. However, after being incubated with $100 \mu \mathrm{M}$ AS for $20 \mathrm{~min}$ the cells, as shown in Fig. $2 \mathrm{~b}$, displayed strong fluorescence. The fluorescence intensity reached a plateau within $20 \mathrm{~min}$, and a time dependence assay 


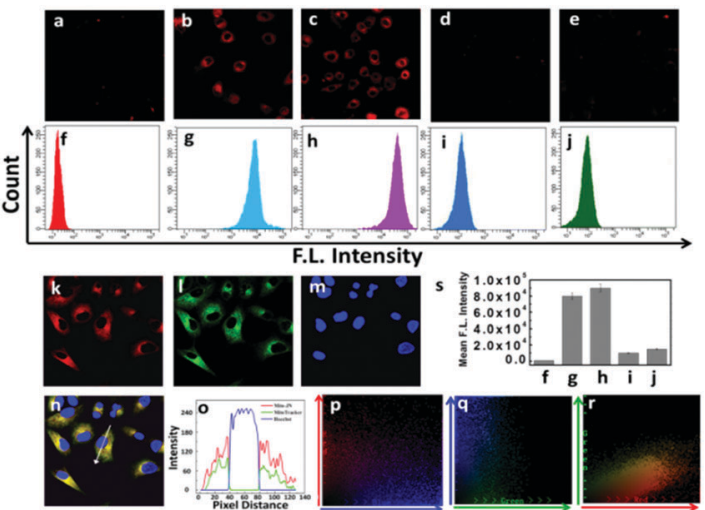

Fig. 2 Confocal microscopy images and flow cytometry assay of RAW 264.7 cells for the detection of HNO. All the cells were incubated with Mito-JN $(1 \mu \mathrm{M})$ for $20 \mathrm{~min}$ and then washed with DMEM to remove the excess probe. (a) RAW264.7 cells were incubated with $1 \mu \mathrm{M}$ Mito-JN for 20 min at $37{ }^{\circ} \mathrm{C}$ and washed with DMEM. (b) Performed as described in part a, but $100 \mu$ M AS was additionally added for $20 \mathrm{~min}$. (c) Performed as described in part a, but NOC-5 (1 mM) and NaHS $(100 \mu \mathrm{M})$ were additionally added for $20 \mathrm{~min}$. (d) After being treated as indicated in part a, cells were incubated with NaHS $(100 \mu \mathrm{M})$. (e) After being treated as indicated in part $a$, cells were stimulated with NOC-5 $(1 \mathrm{mM})$. ( $\mathrm{f}-\mathrm{j})$ Flow cytometry assays of RAW 264.7 cells corresponding to a-e. (k) RAW264.7 cells were incubated with $1 \mu \mathrm{M}$ Mito-JN, and NOC-5 (1 mM) and NaHS $(100 \mu \mathrm{M})$ were then added. (I) Fluorescence imaging of MitoTracker Green FM. (m) Fluorescence imaging of Hoechst 33342. (n) Merged red, green and blue channels. (o) Intensity profiles of regions of interest (white line in n) across cells. (p) Colocalization areas of the red and blue channels selected. (q) Colocalization areas of the green and blue channels selected. (r) Colocalization areas of the green and red channels selected. (s) Mean fluorescence intensity in assays $f-j$. Mito-JN (red channel: $\lambda_{\mathrm{ex}}=680 \mathrm{~nm}, \lambda_{\mathrm{em}}=690-720 \mathrm{~nm}$ ). MitoTracker Green FM showing mitochondria (green channel: $\lambda_{\mathrm{ex}}=488 \mathrm{~nm}, \lambda_{\mathrm{em}}=500-580 \mathrm{~nm}$ ). Hoechst showing nuclei (blue channel: $\lambda_{\mathrm{ex}}=405 \mathrm{~nm}, \lambda_{\mathrm{em}}=425-525 \mathrm{~nm}$ ). The images are representative of $n=5$ independent experiments.

revealed high photostability and a marked increase in the fluorescence of Mito-JN in living cells (Fig. S6, ESI $\dagger$ ), because HNO could be directly derived from the interaction between $\mathrm{NO}$ and $\mathrm{H}_{2} \mathrm{~S}^{55,58}$ Therefore, we investigated the in situ generation of HNO via the employment of Mito-JN in RAW 264.7 cells. RAW 264.7 cells were exposed to NOC-5 (a donor of NO) and/or NaHS (a donor of $\mathrm{H}_{2} \mathrm{~S}$ ) for $20 \mathrm{~min}$ under physiological conditions. The strong fluorescence shown in Fig. 2c was attributed to the endogenous formation of HNO. Cells that were merely treated with NaHS or NOC-5 emitted faint fluorescence (Fig. 2d and e). Because laser scanning confocal microscopy is only valuable in the case of relatively small amounts of cells in visual fields, which might decrease the reliability of the data because of various uncontrolled factors, whereas a flow cytometry assay can provide more statistically reliable data by rapidly and sensitively analyzing millions of cells, ${ }^{59}$ all the fluorescence imaging results were further confirmed via flow cytometry (Fig. $2 \mathrm{f}-\mathrm{j}$ ). In Fig. $2 \mathrm{~s}$, the mean changes in fluorescence corresponding to Fig. $2 \mathrm{f}-\mathrm{j}$ are quantified. These data demonstrated that Mito-JN was available for the detection of the intracellular generation of $\mathrm{HNO}$, and HNO could be formed directly from the reaction of $\mathrm{NO}$ with $\mathrm{H}_{2} \mathrm{~S}$ in physiological conditions.

Metal centers play a pivotal role in the generation of HNO in the $\mathrm{NO} / \mathrm{H}_{2} \mathrm{~S}$ crosstalk signaling pathway, and thus endogenous
HNO will predominantly be generated in mitochondria, as these organelles are richest in heme iron centers. ${ }^{12,60}$ In order to examine the ability of Mito-JN to detect mitochondria, a colocalization experiment was carried out by co-staining with the probe Mito-JN, MitoTracker Green FM (a commercial MitoTracker) and the nuclear stain Hoechst 33342. RAW 264.7 cells, as shown in Fig. $2 \mathrm{k}$, were loaded with $1 \mu \mathrm{M}$ MitoJN for $20 \mathrm{~min}, 2 \mu \mathrm{M}$ Hoechst 33342 for $30 \mathrm{~min}$, and $1 \mu \mathrm{g} \mathrm{mL}$ MitoTracker Green FM for 15 min. The spectrally separated images that were acquired using the three dyes (Fig. 2k-m) were further analyzed using Image-Pro Plus software. Mitochondria were stained with MitoTracker Green FM and exhibited clear fluorescence signals in the green channel (500-580 nm, Fig. 2l). The fluorescence images were merged with the image acquired using Mito-JN, as shown in Fig. 2n. We determined that the Pearson's coefficient was $R_{\mathrm{r}}=0.93$ and the Manders' coefficients were $m_{1}=0.99$ and $m_{2}=0.98$, which implied that Mito-JN was preferentially distributed in mitochondria. An analysis of the color-pair intensity correlation for Fig. $2 \mathrm{k}$ and 1 gave a highly correlated plot for the two dyes used for co-staining (Fig. 2r), whereas a correlation analysis performed for Mito-JN and Hoechst 33342 resulted in discrete pixels (Fig. 2p). The intensity profiles of linear regions of interest (white arrow in Fig. 2n) across the RAW 264.7 cells closely corresponded (Fig. 20). Furthermore, we extracted the mitochondria of RAW 264.7 cells using a Cell Mitochondria Isolation Kit, and flow cytometry analysis of mitochondrial isolation from cells stimulated as shown in Fig. $2 \mathrm{k}$ was also performed to provide secondary evidence of changes in the fluorescence signal of mitochondria (Fig. S7, ESI $\dagger$ ). These results illustrated that the majority of HNO was generated in mitochondria and our probe Mito-JN could specifically target mitochondria for the in situ detection of changes in the level of HNO.

\section{Additional generation of $\mathrm{H}_{2} \mathrm{~S}_{n}$ in $\mathrm{NO} / \mathrm{H}_{2} \mathrm{~S}$ crosstalk}

According to the above experiments, we confirmed that HNO could be formed in the reaction of $\mathrm{NO} / \mathrm{H}_{2} \mathrm{~S}$ crosstalk in cells. Moreover, $\mathrm{H}_{2} \mathrm{~S}_{n}$ were also generated in this interaction. In order to confirm the additional generation of $\mathrm{H}_{2} \mathrm{~S}_{n}$, a previously reported $\mathrm{H}_{2} \mathrm{~S}_{n}$ probe, namely, Cy-Mito, was employed to directly detect $\mathrm{H}_{2} \mathrm{~S}_{n}$. Human astrocytoma (U87) cells were selected as the test cell model. U87 cells were incubated with $1 \mu \mathrm{M}$ Mito-JN for $20 \mathrm{~min}$ and $1 \mu \mathrm{M}$ Cy-Mito for $15 \mathrm{~min}$ at $37{ }^{\circ} \mathrm{C}$ for the simultaneous formation of $\mathrm{H}_{2} \mathrm{~S}_{n}$ and HNO. As shown in Fig. S10a and $\mathrm{d}$ (ESI $\dagger$ ), the HNO channel (Mito-JN) and $\mathrm{H}_{2} \mathrm{~S}_{n}$ channel (Cy-Mito) emitted no fluorescence, which indicated that the levels of $\mathrm{HNO}$ and $\mathrm{H}_{2} \mathrm{~S}_{n}$ in living cells were low. After $1 \mathrm{mM}$ NOC-5 and $100 \mu \mathrm{M}$ NaHS were added to Petri dishes for $10 \mathrm{~min}$, the HNO channel and $\mathrm{H}_{2} \mathrm{~S}_{n}$ channel exhibited fluorescence emissions (Fig. S10b and e, ESI $\dagger$ ), which illustrated that the generation of $\mathrm{HNO}$ and $\mathrm{H}_{2} \mathrm{~S}_{n}$ was sensitively captured by Mito-JN and Cy-Mito, respectively. Remarkable increases in fluorescence signals were observed in the HNO channel and $\mathrm{H}_{2} \mathrm{~S}_{n}$ channel $20 \mathrm{~min}$ later (Fig. S10c and f, ESI $\dagger$ ). All the fluorescence response results were further confirmed via a flow cytometry assay (Fig. S10g-1, ESI $\dagger$ ). The two sets of results were 
closely consistent with each other. The results indicated that $\mathrm{NO}$ and $\mathrm{H}_{2} \mathrm{~S}$ could trigger the formation of $\mathrm{HNO}$ and $\mathrm{H}_{2} \mathrm{~S}_{n}$.

$\mathrm{NO}$ is believed to be enzymatically generated from L-Arg by iNOS, ${ }^{9}$ and $\mathrm{H}_{2} \mathrm{~S}$ is enzymatically formed from L-Cys by CBS, CSE and 3-MST in cells. ${ }^{15}$ We further investigated the endogenous biosynthetic pathways of $\mathrm{HNO}$ and $\mathrm{H}_{2} \mathrm{~S}_{n}$. U87 cells were employed as cell models for overexpression of the four kinds of enzymes. As illustrated in Fig. 3a and b, the cells in groups ii and iii were treated with $3 \mathrm{mM}$ L-Arg and $3 \mathrm{mM}$ L-Cys, respectively, for $30 \mathrm{~min}$. The cells in groups iv-vii overexpressed iNOS, CBS, CSE and 3-MST, respectively, via cell transfection. Group viii overexpressed iNOS, CBS, CSE and 3-MST and was then incubated with $3 \mathrm{mM} \mathrm{L}$-Arg and $3 \mathrm{mM}$ L-Cys for $30 \mathrm{~min}$. Then, we used LPS to stimulate the transfected cells to increase the production of NO in groups iv and viii. All the groups were incubated with $1 \mu \mathrm{M}$ Cy-Mito and $1 \mu \mathrm{M}$ Mito-JN for $20 \mathrm{~min}$ before imaging. The control cells, as shown in Fig. 3a, emitted almost no fluorescence. Groups ii-vii exhibited faint fluorescence, which indicated that the separate production of endogenous NO or $\mathrm{H}_{2} \mathrm{~S}$ in living cells could not induce the formation of high levels of $\mathrm{HNO}$ and $\mathrm{H}_{2} \mathrm{~S}_{n}$. As expected, group viii exhibited strong fluorescence because the simultaneous presence of endogenous $\mathrm{NO}$ and $\mathrm{H}_{2} \mathrm{~S}$ could produce vast amounts of $\mathrm{HNO}$ and $\mathrm{H}_{2} \mathrm{~S}_{n}$. These data demonstrated that endogenous $\mathrm{NO}$ and $\mathrm{H}_{2} \mathrm{~S}$ could interact to induce a burst in the formation of $\mathrm{HNO}$ and $\mathrm{H}_{2} \mathrm{~S}_{n}$.

\section{Anti-inflammatory effect of HNO in cell models}

HNO has the particular ability to treat cardiovascular diseases. HNO also exerts an anti-inflammatory effect in inflammation by suppressing LPS-induced inflammation via inhibition of the NF-кB p65 and p38 MAPK pathways. ${ }^{8,9}$ Here, we selected a BV-2 microglial cell line as a test model to assess the anti-inflammatory effect of HNO. LPS $\left(1 \mu \mathrm{g} \mathrm{mL}^{-1}\right)$ was used to stimulate an inflammatory response in cells. All the cells, as shown in Fig. 4a, were incubated with $1 \mu \mathrm{M}$ Cy-Mito and $1 \mu \mathrm{M}$ Mito-JN for $20 \mathrm{~min}$.
Fluorescence images were acquired by confocal microscopy, and the fluorescence responses were further confirmed via a flow cytometry assay. An Annexin V-FITC Apoptosis Detection Kit was utilized to assess cellular apoptosis and necrosis induced by cellular inflammatory stress. The cells in the control group did not exhibit any fluorescence, and the rate of apoptosis (including early apoptosis and late apoptosis) in the control cells was almost $0.0 \%$. Once they were treated with LPS, the apoptosis rate of the BV-2 microglial cells increased to $60.9 \%$, and dark-field images indicated low levels of $\mathrm{HNO}$ and $\mathrm{H}_{2} \mathrm{~S}_{n}$. The addition of $1 \mathrm{mM}$ NOC-5 to the LPS-treated cells induced faint fluorescence, because the low level of endogenous $\mathrm{H}_{2} \mathrm{~S}$ in inflammatory cells would generate small amounts of $\mathrm{HNO}$ and $\mathrm{H}_{2} \mathrm{~S}_{n}$. The apoptosis rate was $54.4 \%$. Therefore, supplementation with $100 \mu \mathrm{M}$ NaHS resulted in a strong increase in fluorescence in cells. The result indicated that the endogenous generation of NO contributed to the production of $\mathrm{HNO}$ and $\mathrm{H}_{2} \mathrm{~S}_{n}$ under inflammatory stress. The apoptosis rate was reduced to $39.5 \%$. There is no doubt that a strong fluorescence image was obtained when NOC-5 and NaHS were added to the LPS-treated cells. The apoptosis rate was reduced to $14.6 \%$. We also assessed the anti-inflammatory effect of $\mathrm{H}_{2} \mathrm{~S}_{n}$ in an LPS-treated cell model. Even after the addition of $100 \mu \mathrm{M} \mathrm{Na} \mathrm{S}_{4}$ (a donor of $\mathrm{H}_{2} \mathrm{~S}_{n}$ ), the rate of apoptosis was still 49.4\%. To confirm the anti-inflammatory effect of HNO in our cell model, we extracted proteins from all the treated cells illustrated in Fig. 4a. We utilized western blotting analysis to analyze the expression of inflammation-associated proteins, namely, phosphorylated p38 (P-p38), p38 MAPK (T-p38), phosphorylated NF-кB p65 (P-p65) and NF-кB p65 (T-p65). As shown in Fig. 4b, P-p38 and P-p65 were activated in inflammatory cells. In the NOC-5 and $\mathrm{H}_{2} \mathrm{~S}$ groups, the protein expressions of P-p38 and P-p65 decreased because small amounts of HNO were produced. As expected, the protein expressions of P-p38 and P-p65 were drastically reduced after the simultaneous addition of NOC-5 and NaHS. All these data demonstrated that HNO possessed an anti-inflammatory effect
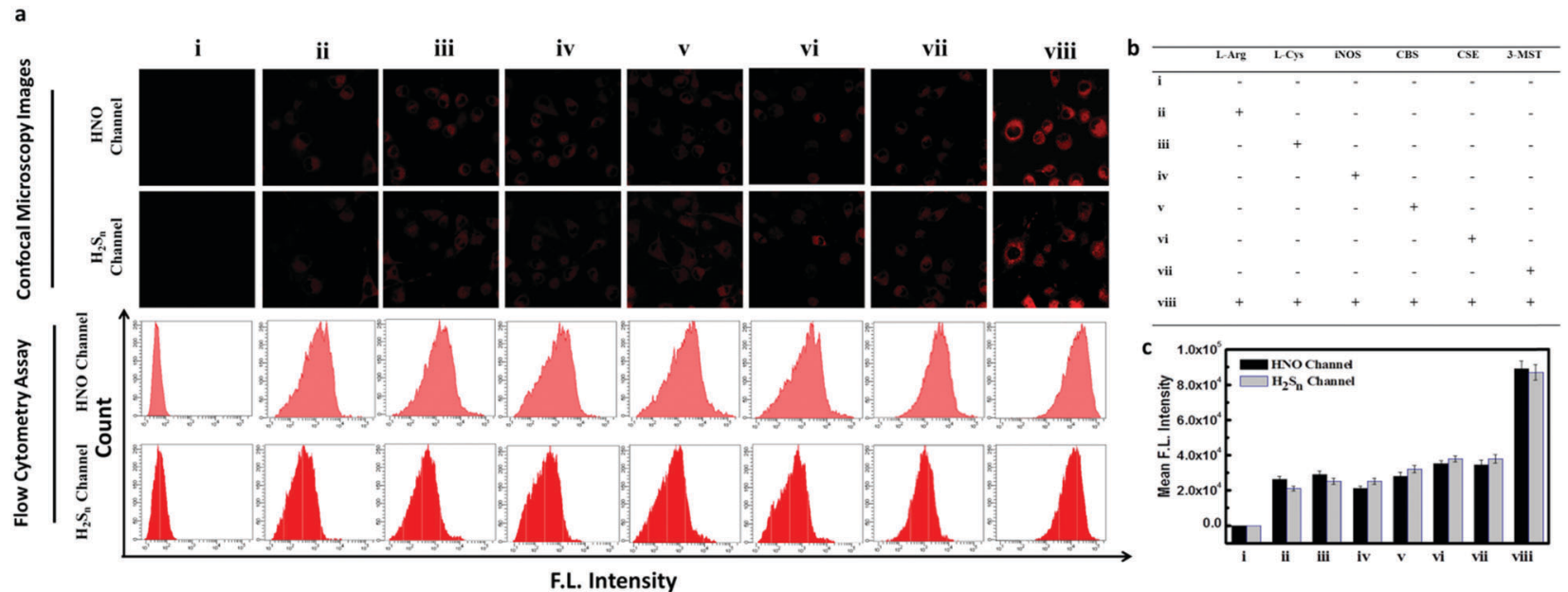

Fig. 3 Generation of endogenous $\mathrm{HNO}$ and $\mathrm{H}_{2} \mathrm{~S}_{n}$ in living U87 cells. (a) Confocal microscopy images and flow cytometry assay of U87 cells for the detection of endogenous $\mathrm{HNO}$ and $\mathrm{H}_{2} \mathrm{~S}_{n}$. (b) Mode of treatment used for the eight groups of cells. (c) Mean fluorescence intensity of the eight groups of cells shown in part a. Mito-JN (red channel: $\lambda_{\mathrm{ex}}=680 \mathrm{~nm}, \lambda_{\mathrm{em}}=690-720 \mathrm{~nm}$ ). Cy-Mito (red channel: $\lambda_{\mathrm{ex}}=730 \mathrm{~nm}, \lambda_{\mathrm{em}}=750-800 \mathrm{~nm}$ ). The images are representative of $n=5$ independent experiments. 

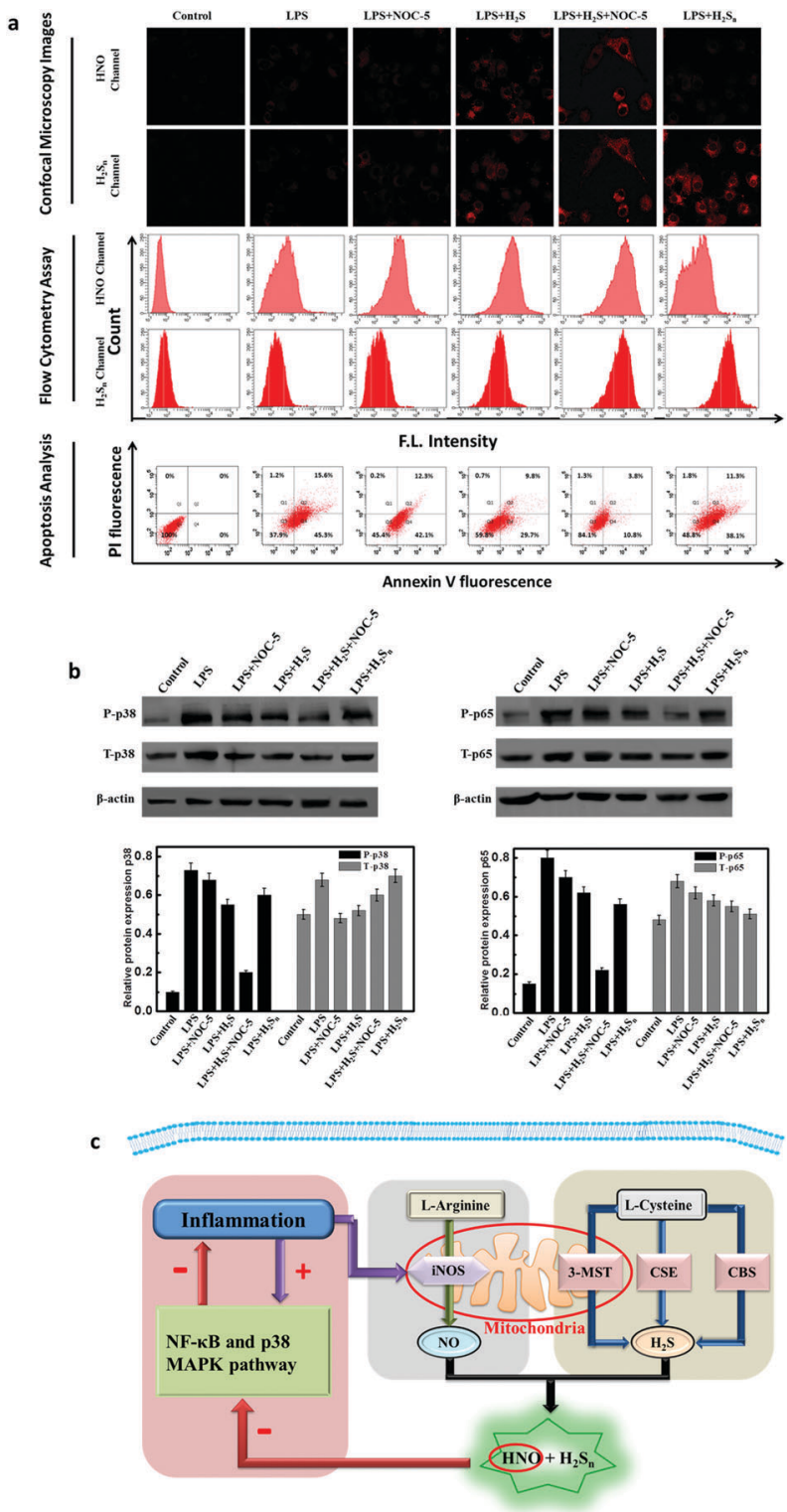

Fig. 4 Anti-inflammatory effect of HNO in inflammatory cell model and protein expressions of P-p38 and P-p65 in cells. (a) Confocal microscopy images, flow cytometry assay and apoptosis analysis of inflammatory cell model for the detection of $\mathrm{HNO}$ and $\mathrm{H}_{2} \mathrm{~S}_{n}$. Apoptosis analysis: (Q1) necrotic, (Q2) late apoptosis, (Q3) viable, (Q4) early apoptosis. (b) Western blotting analysis of P-p38, T-p38, P-p65 and T-p65 from part a. $\beta$-actin was used as a loading control. (c) Illustration of generation of endogenous $\mathrm{HNO}$ and $\mathrm{H}_{2} \mathrm{~S}_{n}$ in living cells. Mito-JN (red channel: $\lambda_{\mathrm{ex}}=680 \mathrm{~nm}, \lambda_{\mathrm{em}}=$ 690-720 nm). Cy-Mito (red channel: $\lambda_{\mathrm{ex}}=730 \mathrm{~nm}, \lambda_{\mathrm{em}}=750-800 \mathrm{~nm}$ ). The images are representative of $n=5$ independent experiments.

in the inflammatory cell model. An illustration of this physiological process is shown in Fig. 4c.

\section{Imaging of HNO in vivo}

Because NIR optical imaging holds great potential for noninvasive detection in vivo, the probe was next used to perform noninvasive imaging in living mice. Mito-JN was further used for in vivo imaging of $\mathrm{HNO}$ in BALB/c mice $(n=5)$ via
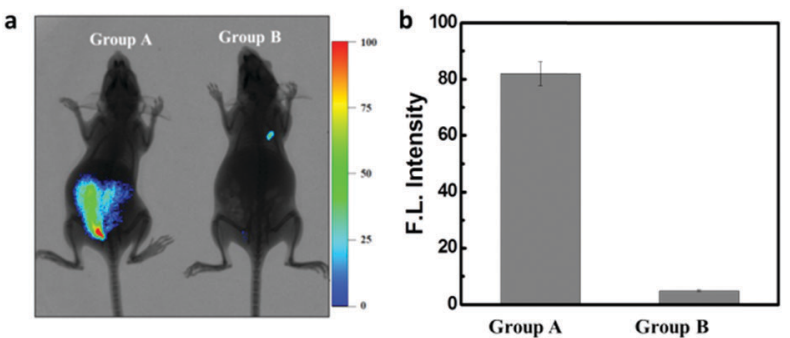

Fig. 5 Fluorescence/X-ray images of BALB/c mice visualizing changes in $\mathrm{HNO}$ levels using Mito-JN. (a) Mice in group A were injected in the peritoneal cavity (i.p.) with $50 \mu \mathrm{M}$ Mito-JN (50 $\mu \mathrm{L}$ in 1:9 DMSO/saline, v/v) for $20 \mathrm{~min}$ and then injected with AS ( $500 \mu \mathrm{M}, 50 \mu \mathrm{L}$ in saline) for a further $20 \mathrm{~min}$. Mice in group B were treated in the peritoneal cavity (i.p.) with $50 \mu \mathrm{M}$ Mito-JN (50 $\mu \mathrm{L}$ in 1: $9 \mathrm{DMSO} / \mathrm{saline}, \mathrm{v} / \mathrm{v}$ ) for $20 \mathrm{~min}$. (b) Mean fluorescence intensities in group $A$ and group $B$. The images displayed represent emission intensities recorded in the window of $690-750 \mathrm{~nm}, \lambda_{\mathrm{ex}}=680 \mathrm{~nm}$. Data are presented as the mean $\pm \operatorname{SD}(n=5)$.

intraperitoneal injection. Mice in group A were first injected with $50 \mu \mathrm{M}$ Mito-JN (50 $\mu \mathrm{L}$ in 1:9 DMSO/saline, $\mathrm{v} / \mathrm{v}$ ) for $20 \mathrm{~min}$. After $500 \mu \mathrm{M}$ AS ( $50 \mu \mathrm{L}$ in saline) was injected for $20 \mathrm{~min}$, strong fluorescence was observed in the entire abdominal cavity of the mice in group A (Fig. 5a). Mice in group B exhibited no fluorescence emission without the injection of AS (Fig. 5a, group B). The average fluorescence intensities are shown for a direct comparison in Fig. 5b. All these results demonstrated that the NIR fluorescent probe Mito-JN could be successfully used for deep imaging of $\mathrm{HNO}$ in living mice without interference from autofluorescence in the organism.

\section{Anti-inflammatory effect of HNO in rat model}

Considering the excellent behavior of Mito-JN for fluorescence imaging in vivo and the remarkable anti-inflammatory function of HNO in cells, we further established a model of gouty arthritis (GA) in Sprague-Dawley (SD) rats to investigate the anti-inflammatory effect of HNO. The GA rats were divided into five groups. All the SD rats were injected with $50 \mu \mathrm{M}$ Mito-JN $(10 \mu \mathrm{L}$ in $1: 9 \mathrm{DMSO} / \mathrm{saline}, \mathrm{v} / \mathrm{v})$ in the ankle joint cavity for $20 \mathrm{~min}$. In the rats in the control group, almost no fluorescence was observed (Fig. 6a). GA rats exhibited faint fluorescence after the probe was injected for $20 \mathrm{~min}$, which indicated low levels of HNO in vivo. The above rats were additionally injected with $1 \mathrm{mM}$ NOC-5 $(10 \mu \mathrm{L})$. A weak fluorescence emission was observed because a small amount of HNO was generated at the inflammation site. However, the additional injection of $100 \mu \mathrm{M}$ NaHS $(10 \mu \mathrm{L})$ resulted in stronger fluorescence images than the additional injection of NOC-5 into the rat ankle joint. This result implied an increase in the level of HNO. As expected, the simultaneous injection of $1 \mathrm{mM}$ NOC-5 $(10 \mu \mathrm{L})$ and $100 \mu \mathrm{M}$ NaHS $(10 \mu \mathrm{L})$ into the ankle joint cavity of GA rats resulted in strong fluorescence. A quantization of the fluorescence intensities is shown for a direct comparison in Fig. S15 (ESI $\dagger$ ). These results demonstrated that HNO could be generated in the rat ankle joint via the reaction between $\mathrm{NO}$ and $\mathrm{H}_{2} \mathrm{~S}$. To confirm the anti-inflammatory effect of HNO on gouty arthritis, we extracted proteins from the synovial membrane tissue of the rat 

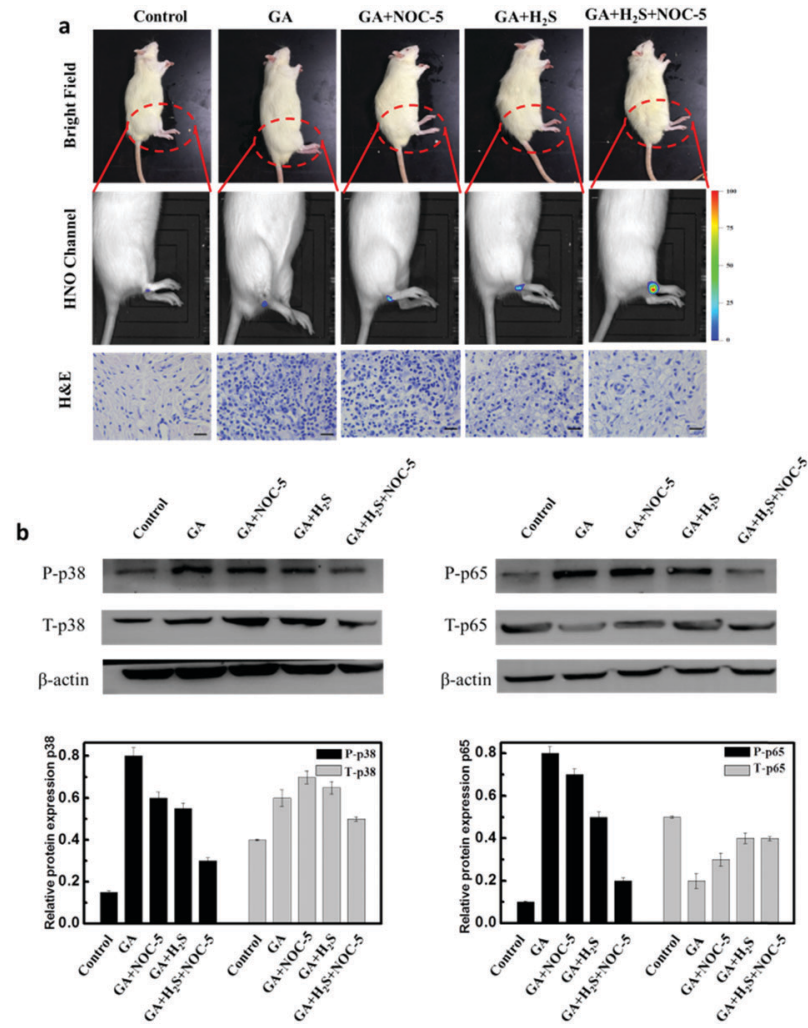

Fig. 6 Representative in vivo NIR fluorescence images visualizing $\mathrm{HNO}$ in a rat model of gouty arthritis. H\&E (hematoxylin and eosin) staining of synovial membrane tissue of the ankle joint and the protein expressions of P-p38 and P-p65 in synovial membrane tissue. (a) Bright-field images of the five groups, fluorescence imaging of $\mathrm{HNO}$ in the five groups, and H\&E staining of synovial membrane tissue in the five groups. Scale bar $=20 \mu \mathrm{m}$. (b) Western blotting analysis of P-p38, T-p38, P-p65 and T-p65 from part a. $\beta$-actin was used as a loading control. The images displayed represent emission intensities recorded in the window of $690-750 \mathrm{~nm}, \lambda_{\mathrm{ex}}=680 \mathrm{~nm}$. Data are presented as the mean \pm SD $(n=5)$.

ankle joint. The protein expressions of phosphorylated p38 (P-p38), p38 MAPK (T-p38), phosphorylated NF-kB p65 (P-p65) and NF-KB p65 (T-p65) were determined to assess the degrees of inflammation in the five groups using western blotting analysis. As shown in Fig. 6b, the results of western blotting illustrated that P-p38 and P-p65 were activated in the GA rat model owing to the development of gouty arthritis. The addition of NOC-5 or NaHS slightly decreased the protein expressions of P-p38 and P-p65 because of the formation of low levels of HNO. A high level of HNO drastically reduced the protein expressions of P-p38 and P-p65 in the GA + NOC- $5+\mathrm{H}_{2} \mathrm{~S}$ group. To prove that the antiinflammatory effect originated from $\mathrm{HNO}$ instead of $\mathrm{H}_{2} \mathrm{~S}_{n}$, we examined the changes in the expressions of P-p38 and P-p65 in GA rats that were pretreated with $100 \mu \mathrm{M} \mathrm{Na}_{2} \mathrm{~S}_{4}(10 \mu \mathrm{L})$ by western blotting (Fig. S16, ESI $\dagger$ ). There were only slight decreases in the expressions of P-p38 and P-p65 in the $\mathrm{GA}+\mathrm{H}_{2} \mathrm{~S}_{n}$ group with respect to the GA + NOC- $5+\mathrm{H}_{2} \mathrm{~S}$ group. The results demonstrated that the anti-inflammatory effect of HNO was stronger than that of $\mathrm{H}_{2} \mathrm{~S}_{n}$. Furthermore, H\&E (hematoxylin and eosin) staining of synovial membrane tissue of the ankle joint was carried out to confirm the degrees of inflammation (Fig. 6a). All these results indicated that HNO exerted an anti-inflammatory effect in gouty arthritis.

\section{Conclusions}

In summary, we have developed an NIR fluorescent probe, namely, Mito-JN, for the examination of the anti-inflammatory effects of HNO in cells and in a rat model of gouty arthritis. Mito-JN exhibits high selectivity and high sensitivity to HNO and low cytotoxicity. The probe can be localized in mitochondria and can be used for the detection of HNO in mice without interference from background fluorescence. We have confirmed that the interaction between $\mathrm{NO}$ and $\mathrm{H}_{2} \mathrm{~S}$ yields $\mathrm{HNO}$ in cells and in vivo. This biosynthetic pathway also involves the generation of endogenous $\mathrm{H}_{2} \mathrm{~S}_{n}$. The results imply that reactive nitrogen species have a close relationship with reactive sulfur species in biological systems. With the help of the probe Mito-JN, we assessed the antiinflammatory effect of $\mathrm{HNO}$ in the $\mathrm{NO} / \mathrm{H}_{2} \mathrm{~S}$ crosstalk signaling pathway in a cell model of LPS-induced inflammation and a rat model of GA. Western blotting analysis and pathological sectioning were also employed to demonstrate the anti-inflammatory effect of HNO. We anticipate that HNO will have huge potential for the treatment of inflammation.

\section{Experimental}

\section{Cell transfection}

A mouse macrophage cell line (RAW264.7 cells), human astrocytoma cells (U87 cells) and a BV-2 microglial cell line (BV-2 cells) were obtained from the Committee on Type Culture Collection of the Chinese Academy of Sciences. U87 cells were chosen as the cell model for the overexpression of iNOS, CSE, CBS and 3-MST using a Calcium Phosphate Cell Transfection Kit. The iNOS, CSE, CBS and 3-MST genes were transiently overexpressed using an iNOS CDNA/ pBiGN, an hCSE cDNA/pIRES2-EGFP, an hCBS cDNA/PCMVSPORT6 or a 3-MST/pCI-HA construct (Vigene Biosciences Co., Ltd). Identical empty vectors that lacked a cDNA insert were used as controls.

\section{Establishment of rat model of gouty arthritis of the ankle joint}

Eight- to ten-week-old SD rats were obtained from Binzhou Medical University. A $0.1 \mathrm{~g} \mathrm{~mL}^{-1}$ sodium urate solution was dissolved in physiological saline. We used needles with a diameter of $0.45 \mathrm{~mm}$ to inject $0.1 \mathrm{~mL}$ sodium urate solution into the rat ankle joint. The rat model of gouty arthritis was completed after 3 days. All experimental procedures were conducted in conformity with institutional guidelines for the care and use of laboratory animals, and protocols were approved by the Institutional Animal Care and Use Committee of Binzhou Medical University, Yantai, China.

\section{Fluorescence imaging of the rat model of gouty arthritis}

The rats used for the model of gouty arthritis were grouphoused on a $12: 12$ light-dark cycle at $22{ }^{\circ} \mathrm{C}$ with free access to food and water. The rats were divided into different groups. Subsequently, the rats received an injection of Mito-JN 
( $50 \mu \mathrm{M}, 50 \mu \mathrm{L}$ in $1: 9 \mathrm{DMSO} /$ saline, $\mathrm{v} / \mathrm{v}$ ) in the ankle joint cavity and were maintained for $20 \mathrm{~min}$. Finally, the five groups of rats were anesthetized by inhalation of isoflurane. Images were taken using a PerkinElmer IVIS Lumina XRMS Series III in vivo imaging system with an excitation filter at $680 \mathrm{~nm}$ and an emission in the range of 700-800 $\mathrm{nm}$. The results were presented as the mean and standard deviation of five separate measurements.

\section{Conflicts of interest}

There are no conflicts to declare.

\section{Acknowledgements}

We thank the National Natural Science Foundation of China (No. 21575159, 21775162, 21405172 and 21575080), the program of Youth Innovation Promotion Association, CAS (Grant 2015170), and the Instrument Developing Project of the Chinese Academy of Sciences (YZ201662).

\section{Notes and references}

1 C.-U. Choe, J. Lewerenz, C. Gerloff, T. Magnus and S. Donzelli, Redox Signaling, 2011, 14, 1699-1711.

2 (a) A. S. Dutton, J. M. Fukuto and K. N. Houk, J. Am. Chem. Soc., 2004, 126, 3795-3800; (b) N. Paolocci, M. I. Jackson, B. E. Lopez, K. Miranda, C. G. Tocchetti, D. A. Wink, A. J. Hobbs and J. M. Fukuto, Pharmacol. Ther., 2007, 113, 442-458; (c) J. C. Irvine, R. H. Ritchie, J. L. Favaloro, K. L. Andrews, R. E. Widdop and B. K. Kemp-Harper, Trends Pharmacol. Sci., 2008, 29, 601-608.

3 M. D. Bartberger, J. M. Fukuto and K. Houk, Proc. Natl. Acad. Sci. U. S. A., 2001, 98, 2194-2198.

4 J. C. Irvine, J. L. Favaloro and B. K. Kemp-Harper, Hypertension, 2003, 41, 1301-1307.

5 N. Paolocci, T. Katori, H. C. Champion, M. E. S. John, K. M. Miranda, J. M. Fukuto, D. A. Wink and D. A. Kass, Proc. Natl. Acad. Sci. U. S. A., 2003, 100, 5537-5542.

6 K.-D. Kroncke, K. Fehsel, T. Schmidt, F. T. Zenke, I. Dasting, J. R. Wesener, H. Bettermann, K. D. Breunig and V. Kolbbachofen, Biochem. Biophys. Res. Commun., 1994, 200, 1105-1110.

7 W. Maret, Adv. Nutr., 2013, 4, 82-91.

8 A. C. Zarpelon, G. R. Souza, T. M. Cunha, I. R. Schivo, M. Marchesi, R. Casagrande, P. Pinge-Filho, F. Q. Cunha, S. H. Ferreira, K. M. Miranda and W. A. Verri Jr., Neuropharmacology, 2013, 71, 1-9.

9 Y. B. Zhou, Z. Y. Wu, X. Cao, L. Ding, Z. S. Wen and J. S. Bian, Pharmacol. Res., 2016, 111, 885-895.

10 Q. C. Yong, J. L. Cheong, F. Hua, L. W. Deng, Y. M. Khoo, H. S. Lee, A. Perry, M. Wood, M. Whiteman and J. S. Bian, Antioxid. Redox Signaling, 2011, 14, 2081-2091.

11 Q. C. Yong, L. F. Hu, S. Wang, D. Huang and J. S. Bian, Cardiovasc. Res., 2010, 88, 482-491.
12 H. Lange, G. Kispal and R. Lill, J. Biol. Chem., 1999, 274, 18989-18996.

13 M. Sharpe and C. Cooper, Biochem. J., 1998, 332, 9-19.

14 A. Boveris, S. Alvarez and A. Navarro, Free Radical Biol. Med., 2002, 33, 1186-1193.

15 B. D. Paul and S. H. Snyder, Nat. Rev. Mol. Cell Biol., 2012, 13, 499-507.

16 D. Gero, B. Szczesny, K. Modis, K. Yanagi, M. E. Wood, A. Perry, C. Szabo and M. Whiteman, International Conference on $\mathrm{H}_{2} \mathrm{~S}$ Biology and Medicine, 2014, pp. S22-S23.

17 M. Fu, W. Zhang, L. Wu, G. Yang, H. Li and R. Wang, Proc. Natl. Acad. Sci. U. S. A., 2012, 109, 2943-2948.

18 R. C. Zanardo, V. Brancaleone, E. Distrutti, S. Fiorucci, G. Cirino and J. L. Wallace, FASEB J., 2006, 20, 2118-2120.

19 R. Miyamoto, S. Koike, Y. Takano, N. Shibuya, Y. Kimura, K. Hanaoka, Y. Urano, Y. Ogasawara and H. Kimura, Sci. Rep., 2017, 7, 45995-46004.

20 (a) V. Marx, Nat. Methods, 2014, 11, 717-720; (b) R. Wang, C. Yu, F. Yu and L. Chen, TrAC, Trends Anal. Chem., 2010, 29, 1004-1013; (c) Y. Yang, Q. Zhao, W. Feng and F. Li, Chem. Rev., 2012, 113, 192-270; (d) X. Li, X. Gao, W. Shi and H. Ma, Chem. Rev., 2013, 114, 590-659; (e) X. Chen, Y. Zhou, X. Peng and J. Yoon, Chem. Soc. Rev., 2010, 39, 2120-2135.

21 M. Royzen, J. J. Wilson and S. J. Lippard, J. Inorg. Biochem., 2013, 118, 162-170.

22 N. Kitamura, T. Hiraoka, K. Tanaka and Y. Chujo, Bioorg. Med. Chem., 2012, 20, 4668-4674.

23 J. Rosenthal and S. J. Lippard, J. Am. Chem. Soc., 2010, 132, 5536-5537.

24 U. P. Apfel, D. Buccella, J. J. Wilson and S. J. Lippard, Inorg. Chem., 2013, 52, 3285-3294.

25 Y. Zhou, K. Liu, J.-Y. Li, Y. Fang, T.-C. Zhao and C. Yao, Org. Lett., 2011, 13, 1290-1293.

26 A. T. Wrobel, T. C. Johnstone, A. Deliz Liang, S. J. Lippard and P. Rivera-Fuentes, J. Am. Chem. Soc., 2014, 136, 4697-4705.

27 Y. Zhou, Y. W. Yao, J. Y. Li, C. Yao and B. P. Lin, Sens. Actuators, B, 2012, 174, 414-420.

28 A. Loas, R. J. Radford, A. Deliz Liang and S. J. Lippard, Chem. Sci., 2015, 6, 4131-4140.

29 X. Sun, G. Kim, Y. Xu, J. Yoon and T. D. James, ChemPlusChem, 2016, 81, 30-34.

30 H. J. Lv, R. F. Ma, X. T. Zhang, M. H. Li, Y. T. Wang, S. Wang and G. W. Xing, Tetrahedron, 2016, 72, 5495-5501.

31 K. Kawai, N. Ieda, K. Aizawa, T. Suzuki, N. Miyata and H. Nakagawa, J. Am. Chem. Soc., 2013, 135, 12690-12696.

32 G. J. Mao, X. B. Zhang, X. L. Shi, H. W. Liu, Y. X. Wu, L. Y. Zhou, W. H. Tan and R. Q. Yu, Chem. Commun., 2014, 50, 5790-5792.

33 Z. Miao, J. A. Reisz, S. M. Mitroka, J. Pan, M. Xian and S. B. King, Bioorg. Med. Chem. Lett., 2015, 25, 16-19.

34 K. N. Bobba, Y. Zhou, L. E. Guo, T. N. Zang, J. F. Zhang and S. Bhuniya, RSC Adv., 2015, 5, 84543-84546.

35 X. T. Jing, F. B. Yu and L. X. Chen, Chem. Commun., 2014, 50, 14253-14256.

36 P. Liu, X. T. Jing, F. B. Yu, C. J. Lv and L. X. Chen, Analyst, 2015, 140, 4576-4583. 
37 P. Liu, X. Y. Han, F. B. Yu and L. X. Chen, Chin. J. Anal. Chem., 2015, 43, 1829-1836.

38 Y. Tan, R. Liu, H. Zhang, R. Peltier, Y. W. Lam, Q. Zhu, Y. Hu and H. Sun, Sci. Rep., 2015, 5, 16979-16988.

39 X. Gong, X. F. Yang, Y. Zhong, Y. Chen and Z. Li, Dyes Pigm., 2016, 131, 24-32.

40 B. Dong, K. Zheng, Y. Tang and W. Lin, J. Mater. Chem. B, 2016, 4, 1263-1269.

41 H. M. Kim and B. R. Cho, Chem. Rev., 2015, 115, 5014-5055.

42 K. Zheng, W. Lin, D. Cheng, H. Chen, Y. Liu and K. Liu, Chem. Commun., 2015, 51, 5754-5757.

43 B. Dong, X. Song, X. Kong, C. Wang, N. Zhang and W. Lin, J. Mater. Chem. B, 2017, 5, 5218-5224.

44 M. Ren, B. Deng, K. Zhou, J. Y. Wang, X. Kong and W. Lin, J. Mater. Chem. B, 2017, 5, 1954-1961.

45 K. Sunwoo, K. N. Bobba, J. Y. Lim, T. Park, A. Podder, J. S. Heo, S. G. Lee, S. Bhuniya and J. S. Kim, Chem. Commun., 2017, 53, 1723-1726.

46 C. Liu, H. Wu, Z. Wang, C. Shao, B. Zhu and X. Zhang, Chem. Commun., 2014, 50, 6013-6016.

47 C. Liu, Y. Wang, C. Tang, F. Liu, Z. Ma, Q. Zhao, Z. Wang, B. Zhu and X. Zhang, J. Mater. Chem. B, 2017, 5, 3557-3564.

48 K. Zheng, H. Chen, S. Fang and Y. Wang, Sens. Actuators, B, 2016, 233, 193-198.

49 H. M. Lv, Y. Chen, J. Lei, C. T. Au and S. F. Yin, Anal. Methods, 2015, 7, 3883-3887.

50 X. Jin, X. Sun, X. Di, X. Zhang, H. Huang, J. Liu, P. Ji and H. Zhu, Sens. Actuators, B, 2016, 224, 209-216.
51 H. T. Zhang, R. C. Liu, Y. Tan, W. H. Xie, H. P. Lei, H. Y. Cheung and H. Y. Sun, ACS Appl. Mater. Interfaces, 2015, 7, 5438-5443.

52 X. Zhu, M. Xiong, H. W. Liu, G. J. Mao, L. Zhou, J. Zhang, X. Hu, X. B. Zhang and W. Tan, Chem. Commun., 2016, 52, 733-736.

53 H. Li, Q. Yao, F. Xu, N. Xu, X. Ma, J. Fan, S. Long, J. Du, J. Wang and X. Peng, Anal. Chem., 2018, 90, 4641-4648.

54 B. Dong, X. Kong and W. Lin, ACS Chem. Biol., 2018, 13, 1714-1720.

55 Y. Zhou, X. Zhang, S. Yang, Y. Li, Z. Qing, J. Zheng, J. Li and R. Yang, Anal. Chem., 2017, 89, 4587-4594.

56 Y. Huang, F. Yu, J. Wang and L. Chen, Anal. Chem., 2016, 88, 4122-4129.

57 M. Murphy and R. Smith, Annu. Rev. Pharmacol. Toxicol., 2007, 47, 629-656.

58 M. Eberhardt, M. Dux, B. Namer, J. Miljkovic, N. Cordasic, C. Will, T. I. Kichko, J. de la Roche, M. Fischer, S. A. Suarez, D. Bikiel, K. Dorsch, A. Leffler, A. Babes, A. Lampert, J. K. Lennerz, J. Jacobi, M. A. Marti, F. Doctorovich, E. D. Hogestatt, P. M. Zygmunt, I. Ivanovic-Burmazovic, K. Messlinger, P. Reeh and M. R. Filipovic, Nat. Commun., 2014, 5, 4381-4397.

59 G. Horstick, T. Kempf, M. Lauterbach, M. Ossendorf, L. Kopacz, A. Heimann, H.-A. Lehr, S. Bhakdi, J. Meyer and O. J. Kempski, J. Surg. Res., 2000, 94, 28-34.

60 J. L. Miljkovic, I. Kenkel, I. Ivanović-Burmazović and M. R. Filipovic, Angew. Chem., Int. Ed., 2013, 52, 12061-12064. 